\title{
Analysis of automobile load signal based on AR model
}

\author{
Hong-Feng Wei \\ College of Engineering, Bohai University, Jinzhou china \\ e-mail:weihf951@163.com
}

\begin{abstract}
The AR model was used to extract the simulation of the automobile load signal in this article. By the proper sample data, the feature vector of different automobile load signal can achieve the requirements of load determination with parameter model method. Experimental results showed that the feature selection and load determination can be achieved in automobile load signals. That means, the AR model parameters is effective in analyzing the automobile load determination.
\end{abstract}

Keywords: AR model; High way; automobile vibration signal; feature vector.

\section{Introduction}

According to regulation on administration of highway transfinite transport vehicle, the vehicle load carrying capacity is based on the axle quality not the length. E. above quality of vehicle axle load in the following: single shaft (tyre) on each side load quality $6000 \mathrm{~kg}$; Single shaft (dual tire) on each side load quality $10000 \mathrm{~kg}$; Double shaft (tyre) on each side load quality $10000 \mathrm{~kg}$; Each side double axis (a single tires, tires) load quality $14000 \mathrm{~kg}$; Double shaft (dual tire) on each side load quality $18000 \mathrm{~kg}$; The joint axis (tyre) on each side load quality $12000 \mathrm{~kg}$; The joint axis (dual tire) on each side load quality 22000 kilograms[1].

In terms of governance overrun overload, seven ministries jointly issued "on the national vehicle overrun overload management work of the implementation of the plan, all vehicles cannot exceed the following when loading the first (1) to (5) the transfinite standards set by the kinds of situations, and can't exceed the overload to the standards set by the first (6) kinds of situations. (1) two axis vehicles, the car more than 20 tons of cargo gross weight; (2) three axis vehicles, the vehicle cargo gross weight more than 30 tons of (double shaft calculation according to the two axis, the joint axis according to the three axis calculation, hereinafter the same). (3) four axis vehicles, the total weight of goods more than 40 tons of the car; (4) five axis vehicles, the car of the total weight of goods more than 50 tons; (5) More than six axis and six axis vehicles, the car cargo gross weight more than 55 tons; (6) though not more than the above five kinds 
of standard, but the quality of vehicle loading more than vehicle license approved quality [2].

Generally, national and provincial uniaxial load weight cannot exceed 10 tonnes gross, mass of goods in vehicle cannot exceed the number of axes $* 10$ tons, 6 and 6 axis goods vehicles and above cannot exceed 55 tons.

Whether on the highway or ordinary road, the heavy trucks will cause great damage to the road. The analysis of the results whether trucks overloaded or the damages to the road will be in production and living has very important value in engineering application.

\section{AR Model}

The $A R$ models satisfy the following differential equations:

$$
y(n)=\sum_{i=1}^{p} a_{i} y(n-i)+e(n)
$$

$e(n)$ is the white noise sequence with the average of input zero and variance $\sigma^{2}$. The model of Equation (1) is called p order autoregressive model or abbreviated for AR (p) model. Its transfer function is:

$$
H_{A R}(z)=\frac{1}{A(z)}=1 /\left(1+\sum_{k=1}^{p} a_{k} z^{-k}\right)
$$

The output power spectrum is:

$$
S_{x x}(z)=\sigma^{2} /\left[A(z) A\left(z^{-1}\right)\right]
$$

or

$$
S_{x x}\left(e^{j \omega}\right)=\frac{\sigma^{2}}{\left|A\left(e^{j \omega}\right)\right|^{2}}=\sigma^{2} /\left|1+\sum_{k=1}^{p} a_{k} e^{-j \omega k}\right|^{2}
$$

This model is an all-pole model [3].

\section{Model Order Selection}

Akaike criterion was the basis for determining the model order. The definition is:

$$
A I C(i)=N \ln \hat{\sigma}_{i}^{2}+2 i
$$

Where, $\sigma_{i}^{2}$ is the maximum likelihood estimation of white noise variance in AR process, $N$ is the number of data samples, $i$ is the order of the model [3]. 


\section{Parameter Identification for Automobile Load type}

After the text edit has been completed, the paper is ready for the template. Duplicate the template file by using the Save As command, and use the naming convention prescribed by your conference for the name of your paper. In this newly created file, highlight all of the contents and import your prepared text file. You are now ready to style your paper; use the scroll down window on the left of the MS Word Formatting toolbar.

\subsection{Leakage alarm rate}

Leakage alarm is important in pattern recognition. In the practical project, the leak alarm rate $\alpha$ is generally between 0 and 1 and usually obtained accurately after using $\mathrm{U}$ test.

The calculation equation is [3]:

$$
u=\frac{\left|\mu_{1}-\mu_{2}\right|}{\sqrt{\sigma_{1}^{2} / n_{1}+\sigma_{2}^{2} / n_{2}}} \geq u_{\alpha / 2}
$$

$\mu_{1}$ and $\mu_{2}$ are the average speed, $\sigma_{1}^{2}$ and $\sigma_{2}^{2}$ are the variance sample. $n_{1}$ and $n_{2}$ are the sample number of the small and large vehicle type respectively.

\subsection{False alarm rate}

False alarm is similar with leakage alarm and it is also between 0 and 1.The calculation is as follows [4]:

$$
\begin{gathered}
\beta=\left\{\text { make } \mu_{2} \text { as } \mu_{1} \text { wrongly }\right\}=\phi\left(x_{1}\right)-\phi\left(x_{2}\right) \\
x_{1}=\frac{\left(\mu_{1}-\sqrt{\sigma_{1}^{2} / n_{1}}\right)-\mu_{2}}{\sqrt{\sigma_{1}^{2} / n_{1}}}, x_{2}=\frac{\left(\mu_{1}+\sqrt{\sigma_{1}^{2} / n_{1}}\right)-\mu_{2}}{\sqrt{\sigma_{1}^{2} / n_{1}}}
\end{gathered}
$$

In the equation above, $\sigma_{1}^{2}$ and $\sigma_{2}^{2}$ are the variance of small and large type respectively. $\phi(\bullet)$ can be found from the Gauss distribution table.

\section{Analysis and Research of Automobile Load Signals}

The maximum load of truck and body weight used in the experiment is $30 \mathrm{~kg}$ and $7.2 \mathrm{~kg}$ respectively. In the laboratory, the trucks were divided into 3 cases, including unloaded, half loaded and full loaded. The AR model order was chosen as 7 and 8 to do the signal power spectrum estimation individually. The results can be shown in Table 1 and Table 2 . 
TABLE I. AR MODEL ORDER WAS 7

\begin{tabular}{lllllllll}
\hline parameter & $a 0$ & $a 1$ & $a 2$ & $a 3$ & $a 4$ & $a 5$ & $a 6$ & $a 7$ \\
\hline loadless & 1.00 & -0.99 & -0.09 & -0.26 & 0.195 & -0.06 & 0.23 & -0.01 \\
1/2 load & 1.00 & -0.94 & -0.07 & -0.29 & 0.15 & -0.10 & 0.24 & 0.03 \\
full-laden & 1.00 & -0.83 & -0.02 & -0.31 & 0.09 & -0.12 & 0.21 & 0.01 \\
$\mathrm{U} 1$ & $\mathrm{NaN}$ & 1.11 & 0.03 & 1.00 & 1.71 & 0.50 & 0.85 & 0.54 \\
$\mathrm{U} 2$ & $\mathrm{NaN}$ & 1.92 & 0.39 & 1.43 & 2.22 & 1.26 & 0.07 & 0.16 \\
$\mathrm{U} 3$ & $\mathrm{NaN}$ & 1.62 & 0.89 & 0.55 & 0.88 & 1.09 & 1.67 & 0.60 \\
$\alpha 1$ & & & & & 0.1 & & & \\
$\alpha 2$ & & 0.1 & & 0.2 & 0.05 & & & \\
$\alpha 3$ & & 0.2 & & & & & 0.1 & \\
$\beta 1$ & & & & & 0.19 & & & \\
$\beta 2$ & & 0.16 & & 0.29 & 0.09 & & & \\
$\beta 3$ & & 0.20 & & & & & 0.19 & \\
\hline
\end{tabular}

TABLE II. AR MODEL ORDER WAS 8

\begin{tabular}{llllllllll}
\hline parameter & $a 0$ & $a 1$ & $a 2$ & $a 3$ & $a 4$ & $a 5$ & $a 6$ & $a 7$ & $a 8$ \\
\hline loadless & 1.00 & -0.99 & -0.06 & -0.29 & 0.23 & -0.10 & 0.23 & -0.10 & 0.11 \\
1/2 load & 1.00 & -0.89 & -0.06 & -0.31 & 0.16 & -0.14 & 0.21 & -0.10 & 0.16 \\
full-laden & 1.00 & -0.80 & -0.09 & -0.31 & 0.08 & -0.19 & 0.19 & -0.11 & 0.19 \\
U1 & $\mathrm{NaN}$ & 1.07 & 0.14 & 0.97 & 1.76 & 0.59 & 1.02 & 1.27 & 0.34 \\
$\mathrm{U} 2$ & $\mathrm{NaN}$ & 1.84 & 0.51 & 1.57 & 2.25 & 1.33 & 0.29 & 0.74 & 0.62 \\
$\mathrm{U} 3$ & $\mathrm{NaN}$ & 1.46 & 0.83 & 0.67 & 0.88 & 0.91 & 1.15 & 1.31 & 0.29 \\
$\alpha 1$ & & & & & 0.1 & & & & \\
$\alpha 2$ & & 0.1 & & 0.2 & 0.05 & 0.2 & & & \\
$\alpha 3$ & & 0.2 & & & & & & 0.2 & \\
$\beta 1$ & & & & & 0.18 & & & & \\
$\beta 2$ & & 0.19 & & 0.25 & 0.09 & 0.33 & & & \\
$\beta 3$ & & 0.26 & & & & & & 0.17 & \\
\hline
\end{tabular}

Utest: $P=0.01, k=-2.57 ; P=0.05, k=-1.96 ; P=0.1, k=-1.64 ; P=0.2, k=-1.28$

In Table 1 and Table 2, $U 1, U 2$ and $U 3$ are $U$ test parameters of loadless, $1 / 2$ load and full-laden automobiles respectively; $\alpha 1, \alpha 2$ and $\alpha 3$ are leakage alarm rate of unloaded, 1/2 load and full-laden automobiles respectively; $\beta 1, \beta 2$ and $\beta 3$ are false alarm rate of unloaded, 1/2 load and full-laden automobiles respectively; Suppose the speed of unloaded, 1/2 load and full-laden automobiles are $\mu_{1}, \mu_{2}$ and $\mu_{3}$, respectively. $\mu_{1}>\mu_{2}>\mu_{3}$.

As can be seen from the Table.1 and Table.2, for 7 order parameters, there is only one identification indicator for loadless and 1/2 load automobiles, that is $\alpha 1=0.1, \beta 1=0.19$; there are three identification indicators for loadless and full-laden automobiles, that is $\alpha 2=0.1,0.2$ and $0.05, \beta 2=0.16,0.29$ and 0.09 ; there are two identification indicators for $1 / 2 \mathrm{load}$ and full-laden automobiles, that is $\alpha 3=0.2$ and $0.1, \beta 3=0.20$ and 0.19 ; for 8 order parameters, there is only one identification indicator for loadless and $1 / 2$ load automobiles, that is $\alpha 1=0.1$, 
$\beta 1=0.18$; there are four identification indicators for loadless and full-laden automobiles, that is $\alpha 2=0.1,0.2,0.05$ and $0.2, \beta 2=0.19,0.25,0.09$ and 0.33 ; there are two identification indicators for $1 / 2$ load and full-laden automobiles, that is $\alpha 3=0.2$ and $0.1, \beta 3=0.26$ and 0.17 .

As can be seen from the above data, the model parameters have little difference for unloaded and half loaded automobiles in the experiment. Because the definition of $1 / 2$ load is to analyze simply. In this case, we cannot use parameter model approach with fewer goods. There is a significant difference of model parameters when the automobiles are loadless and full-laden (here, the full-laden does not mean the actual capacity weight, it is the goods in the automobiles). There are three identification indicators for loadless and full-laden automobiles for 7 order model, that is $\alpha 2=0.1,0.2$ and $0.05, \beta 2=0.16,0.29$ and 0.09 ; there are four identification indicators for loadless and full-laden automobiles for 8 order model, that is $\alpha 2=0.1,0.2,0.05$ and $0.2, \beta 2=0.19,0.25$, 0.09 and 0.33; And conducting multiple programs can be selected to identify. The model parameters have difference for $1 / 2$ load and full-laden automobiles in the experiment, but the difference is not very obvious. The reason is that the loaded is far from its maximum load. The so-called 1/2 load and full-laden is very similar.

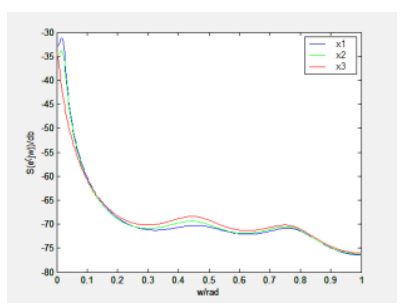

Fig.1. The power spectrum curve of loadless, 1/2 load and full-laden automobiles for 7 order parameters

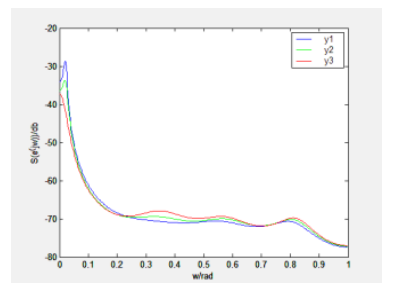

Fig.2. the power spectrum curve of loadless, 1/2 load and full-laden automobiles for 8 order parameters

\section{Conclusion}

In this paper, the parameter model was used in the extract of automobile load signals. By the proper sample data, the feature vector of different automobile load signal can achieve the requirements of load determination with parameter model 
method. And conducting multiple programs can be selected to identify. That is $\alpha=0.2,0.1$ and 0.05 .

Experimental results showed that the feature selection and load determination can be achieved in automobile load signals. That means, the AR model parameters is effective in analyzing the automobile load determination.

\section{Acknowledgement}

This work was supported in part by National Nature Science Foundation under Grant 61104071, 61401043, Program for Liaoning Excellent Talents in. University under Grant LJQ2012095.

\section{References}

1. Regulations of overloaded vehicles transporting in the road [N]. Department of Transportation, 2000.

2. The implement programs on vehicle overloading treatment nationally $[\mathrm{N}]$. Ministry of Communications, Ministry of Public Security, Development and Reform Commission, General Administration of Quality, Safety Authority Department, the state administration for industry and commerce, Legal office. 2004.

3. T. Y. Yao, and H. Sun, Modern digital signal processing, science press of huazhong university, 1999.

4. Z. F. Li and W.S. Gao, Mathematical Statistics and Stochastic Processes, science press of jilin university, 2000.

5. Y. T. Mao, Error theory and precision analysis, National Defence Industry Press, 1982. 